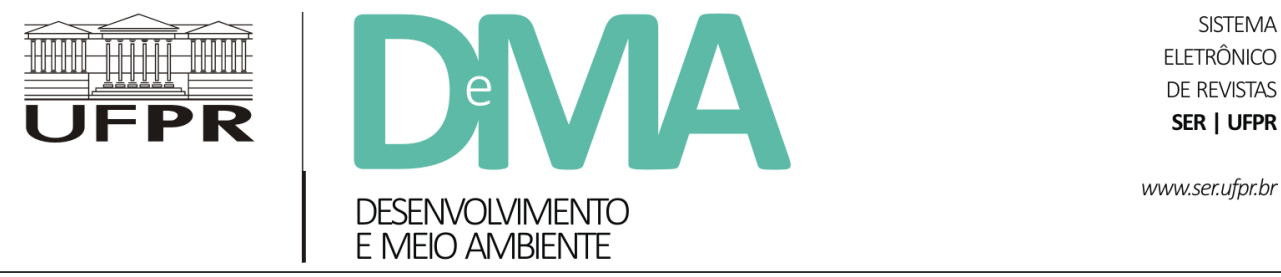

\title{
Concepção de um modelo para avaliação da sustentabilidade no processo produtivo do suco de uva orgânico
}

\section{Developing a Framework to Evaluate the Sustainability of the Production Process of Organic Grape Juice}

\author{
Camila FAGUNDES ${ }^{1 *}$, Dusan SCHREIBER ${ }^{1}$ \\ ${ }^{1}$ Programa de Pós-graduação em Qualidade Ambiental, Universidade Feevale, Novo Hamburgo, RS, Brasil. \\ *E-mail de contato: cfagundes.adm@gmail.com
}

Artigo recebido em 15 de dezembro de 2016, versão final aceita em 21 de julho de 2017.

\begin{abstract}
RESUMO: A incorporação de objetivos estratégicos nas empresas, baseados nos princípios da sustentabilidade, implica trabalhar de forma equilibrada a equidade social, a eficiência econômica e o desempenho ambiental. Para viabilizar esse processo, julga-se relevante propor um conjunto de indicadores de sustentabilidade para que a indústria tenha condições de mensurar aspectos que facultem seu direcionamento para as atividades voltadas à produção sustentável, de modo a contribuir para o desenvolvimento sustentável. Nesse contexto, este artigo tem como objetivo geral propor e analisar um conjunto de indicadores de sustentabilidade empresarial, alinhados com o modelo Triple Bottom Line (TBL), que seja mais adequado para o processo produtivo de suco de uva orgânico. O delineamento metodológico julgado mais adequado foi o estudo de caso múltiplo com abordagem qualitativa e quantitativa. Os resultados obtidos mostram que o trabalho é inovador por apresentar um conjunto de indicadores específicos nas dimensões ambiental (9), econômica (5) e social (8), totalizando 22 indicadores de sustentabilidade para o processo de produção de suco de uva orgânico.
\end{abstract}

Palavras-chave: processo produtivo; produto orgânico; sustentabilidade industrial; TBL.

ABSTRACT: The adoption of strategic objectives by companies, based on sustainability principles, implies working social equity, economic efficiency and environmental performance in a balanced way. In order to enable this process, it is relevant to propose a set of sustainability indicators, so the industry can evaluate aspects that guide its activities towards sustainable production, thus contributing to sustainable development. Considering these aspects, this article aims at proposing and analyzing a set of business sustainability indicators, based on the Triple Bottom Line (TBL) perspective, considered to be more suitable for the production process of organic grape juice. Multiple case study with qualitative and quantitative approach was adopted. The results obtained show that the work is innovative for presenting a set of specific indicators for the production process of organic grape juice in the environmental (9), economic (5) and social (8) dimensions.

Keywords: production process; organic product; industrial sustainability; TBL. 


\section{Introdução}

Desde a década de 1990, o Brasil vem observando um crescimento da produção das atividades vinculadas às subáreas do agronegócio. Além de proporcionar o abastecimento interno de alimentos, valores recordes de exportação foram constatados desde o crescimento mencionado, o que contribuiu diretamente para a geração de divisas (Guedes et al., 2014; Santos et al., 2016). Entretanto, muitas vezes esses valores estão vinculados a uma agricultura convencional, marcada pela utilização de mecanismos - como agrotóxicos e fertilizantes químicos que contribuem para a produção em grande escala, mas que são considerados prejudiciais à saúde humana, ao meio ambiente e, ainda, favorecem o êxodo rural (Benitez \& Golinski, 2007; Kamiyama et al., 2011; Alencar et al., 2013; Capellesso \& Cazella, 2013; Rauta et al., 2014).

Diferente disso, com um cultivo em pequena escala, a produção orgânica é amplamente conhecida por ser um sistema sustentável, pois produz alimentos através de uma agricultura socialmente mais justa, economicamente viável e ecologicamente apropriada (Benitez \& Golinski, 2007; Gabriel et al., 2013; Rauta et al., 2014). Para Azevedo (2012), os alimentos orgânicos podem ser considerados de maior qualidade por serem cultivados em solos com maior equilíbrio de nutrientes, e por sua produção não conter agrotóxicos e fertilizantes sintéticos. Assim, a agricultura orgânica, além de beneficiar o meio ambiente e a saúde humana, ainda evidencia elementos de cunho social que propiciam a preservação da identidade cultural dos envolvidos no processo (Graziano et al., 2011). No entanto, esse tipo de produção ainda enfrenta algumas barreiras como: aprendizado do manejo orgânico, falta de tecnologia apropriada, falta de capacidade de investimento, falta de mão de obra especializada, dificuldades gerenciais, entre outros (Assis \& Romeiro, 2007; Cruz et al., 2010).

Estima-se que atualmente existam cerca de dois milhões de agricultores orgânicos no mundo e que o comércio venda 60 bilhões de dólares em produto, dando suporte a um mercado em crescimento de aproximadamente $20 \%$ ao ano (Dias et al., 2015). A procura por esses alimentos tem sido uma tendência para consumidores preocupados com a saúde, com o bem-estar e também com o meio ambiente (Kamiyama et al., 2011; Andrade \& Bertoldi, 2012; Dias et al., 2015).

Quando os orgânicos são processados, como o suco de uva por exemplo, eles passam a gerar maiores impactos em decorrência da transformação de recursos, na maioria das vezes naturais, em produto final (Corazza, 2003; Oliveira Neto et al., 2015). Entre os principais impactos destaca-se: consumo de energia e água, geração de resíduos sólidos e efluentes químicos, emissões atmosféricas, e outros (Linke et al., 2013; Chen et al., 2014).

Contudo, embora a indústria seja considerada uma fonte de degradação e de esgotamento de recursos, ela é extremamente importante para o desenvolvimento econômico através, por exemplo, da geração de empregos. Nesse sentido, é imprescindível identificar e implantar práticas inovadoras sustentáveis, - principalmente nos processos produtivos - que possam reduzir os impactos negativos ao meio ambiente (Azapagic \& Perdan, 2000; Bork et al., 2014; Calazans \& Silva, 2016).

A fim de continuar com a ideia de produto sustentável, apesar de este passar por um processo produtivo, é extremamente importante a criação de indicadores de sustentabilidade para mensurar, 
monitorar e avaliar o estado atual desse processo e, dessa forma, poder reduzir ao máximo os impactos negativos gerados pela sua transformação do produto (Tokos et al., 2012). De forma complementar, tais indicadores também contribuem para o alcance da sustentabilidade empresarial e para o desenvolvimento sustentável, conceitos que foram difundidos na década de 1980 e que destacam a relação harmônica entre os seres humanos e o meio ambiente como fator determinante para o desenvolvimento futuro da humanidade.

Conceber e implantar os indicadores de sustentabilidade em uma empresa exige, primeiramente, o reconhecimento de que eles precisam ser de fácil acesso e entendimento, além de representarem a real situação do momento, de forma rápida e clara para os tomadores de decisão viabilizarem o planejamento do futuro (Costa, 2010; Linke et al., 2013; Chen et al., 2014). De forma geral, os indicadores demonstram os pontos positivos e negativos, caso existam, para que a comunidade ou a gerência de uma organização possa tomar decisões de forma racional, movendo-se em direção a uma produção mais sustentável (Tokos et al., 2012). Para Veleva et al. (2001), os indicadores de sustentabilidade possuem três objetivos-chave: (1) aumentar a consciência e a compreensão; (2) informar a tomada de decisão; e (3) medir o progresso em direção às metas estabelecidas.

Ademais, a incorporação dos objetivos estratégicos nas empresas, objetivos esses baseados nos princípios da sustentabilidade, implica trabalhar de forma equilibrada a equidade social, a eficiência econômica, e o desempenho ambiental, abordagem conhecida como Tripé da Sustentabilidade (Triple Bottom Line) (Azapagic \& Perdan, 2000; Azapagic, 2003; Krajnc \& Glavic, 2005; Van Bellen, 2006;
Kinderyte, 2008; Singh et al., 2012; Elkington, 2012; Chen et al., 2014).

Além dos indicadores de sustentabilidade, é de extrema importância destacar alguns números relevantes sobre o cultivo de uva no Rio Grande do Sul, para frisar a relevância desse estudo. O estado, mais especificamente as regiões da Serra Gaúcha, da Campanha, da Serra do Sudeste e a região dos Campos de Cima da Serra, possui a maior concentração de viticultura do país. Atualmente, essas regiões são responsáveis por cerca de $90 \%$ da produção nacional de uvas. Apenas no ano de 2015, o estado cultivou, aproximadamente, 703 milhões de $\mathrm{kg}$ de uva, o que demonstra uma evolução em relação a 2005, quando a produção ficou entre 494 milhões de kg (Callado, 2010; União Brasileira de Viticultura (UVIBRA), 2015; Ministério da Agricultura e Pecuária (MAPA, 2015).

A produção de vinhos, de sucos e de derivados mostrou um crescimento de 2,60\% entre os anos de 2013 e 2014 no Rio Grande do Sul, chegando a 507,84 milhões de litros. Para a Embrapa Uva e Vinho (2015), o segmento de suco tem sido uma alternativa para a sustentabilidade da vitivinicultura brasileira, uma vez que os vinhos nacionais vêm experimentando grande concorrência devido à forte inserção de vinhos importados no mercado.

É importante destacar que os dados relacionados ao cenário da viticultura gaúcha - traçado pela União Brasileira de Viticultura, pelo Instituto Brasileiro do Vinho e pela Embrapa Uva e Vinho - não apresentam dados separados para a produção de uvas e sucos de uva orgânicos (UVIBRA, 2015). Dados levantados pela Emater/RS, todavia, identificaram um aumento de 90 hectares destinados à produção de uvas em 2005 para 517 hectares em 2011. Isso corresponde a um aumento de 1000 para 
7000 toneladas destinadas ao consumo in natura e à produção de sucos e vinhos (Camargo et al., 2011).

Diante da importância do cultivo de uva no Estado do Rio Grande do Sul, em especial para a produção de sucos de uva, bem como da crescente preocupação sobre questões relacionadas à sustentabilidade, este artigo tem como problemática de pesquisa o seguinte questionamento: quais são os indicadores de sustentabilidade, a partir da perspectiva TBL, mais apropriados para o processo produtivo do suco de uva orgânico? Para responder a questão, estabeleceu-se como objetivo geral propor e analisar um conjunto de indicadores de sustentabilidade para o processo produtivo do suco de uva orgânico. Para atingir esse objetivo, utilizou-se uma metodologia descritiva, com abordagem qualitativa e quantitativa por meio de um estudo de caso múltiplo.

Considera-se este estudo de caráter inovador, pois contribui para o debate a cerca das temáticas propostas, bem como proporciona um conjunto de indicadores específicos para uma das áreas mais geradoras de impactos negativos ao meio ambiente: o processo produtivo, em especial a produção de suco de uva orgânico.

\section{Metodologia para a seleção dos indicadores}

Um dos primeiros passos considerados essenciais na composição de indicadores de sustentabilidade é a definição de metas e de objetivos a serem alcançados com o conjunto proposto. Para Delai \& Takahashi (2008) e Rabelo \& Lima (2012), essa fase é crucial, uma vez que define o que se pretende alcançar através da mensuração. Para isso, aspectos como missão, visão e valores das empresas foram considerados como pontos norteadores para o estudo, pois demostram a realidade, os valores e a cultura de cada organização (Keeble et al., 2003; Nuintin \& Nakao, 2010). Para Azapagic (2003), os indicadores de sustentabilidade precisam refletir as características específicas de cada empresa.

Para a escolha dos indicadores de sustentabilidade na produção do suco de uva orgânico, foram propostas três etapas. Na primeira, revisou-se a literatura, que compreende, segundo Prodanov \& Freitas (2013), a identificação e a análise de textos já produzidos e disponibilizados publicamente sobre o assunto. No estudo em questão, a revisão bibliográfica foi realizada por meio de consulta às bases de dados Science Direct e Scielo, utilizando como expressão-chave "indicadores de sustentabilidade". Os resultados apresentados foram filtrados por meio de um recorte temporal de vinte anos. Todos os títulos, resumos e palavras-chave foram lidos para escolher os artigos a serem utilizados. Como critério de escolha, foram selecionados apenas os artigos que abordavam a sustentabilidade na dimensão TBL para que alguns indicadores já fossem identificados. Além disso, foram consultados livros já publicados sobre o tema para que alguns conceitos específicos fossem esclarecidos. Para Singh et al. (2012), a identificação de indicadores de sustentabilidade pode ser iniciada por meio de uma listagem simples baseada na teoria, em uma análise empírica, ou na intuição dos pesquisadores e dos stakeholders participantes do estudo.

Na segunda fase, a etapa empírica do estudo, optou-se pela realização de um estudo de caso múltiplo. Para Yin (2010) e Prodanov \& Freitas (2013), esse tipo de estudo tem como objetivo estudar uma situação de forma aprofundada, seja ela um indivíduo, uma família ou uma comunidade. Sendo 
assim, neste estudo, realizou-se uma pesquisa em três organizações industriais do segmento de produção de suco de uva bordô orgânico, localizadas na serra gaúcha, mais especificamente no município de Garibaldi. Elas são classificadas, de acordo com o Serviço Brasileiro de Apoio às Micro e Pequenas Empresas (SEBRAE, 2016), como pequenas empresas, pois seu faturamento (somatório dos ganhos obtidos) anual varia entre $\mathrm{R} \$ 360.000,00 \mathrm{e}$ $\mathrm{R} \$ 3.600 .000,00$.

Os critérios de seleção das três organizações que compõe o estudo foram acessibilidade e conveniência. Essa forma de escolha encontra amparo na literatura que versa sobre o delineamento metodológico. Conforme Prodanov \& Freitas (2013), o pesquisador pode selecionar os elementos aos quais tenha acesso, admitindo que eles possam representar o universo.

A identificação das referidas indústrias resultou de um processo de pesquisa que iniciou com o mapeamento das indústrias de suco de uva orgânico localizadas no estado do Rio Grande do Sul. Na sequência, a pesquisadora entrou em contato com todas as empresas encontradas, solicitando a autorização para a realização da pesquisa. Após um mês, obteve-se retorno de apenas três organizações, as quais foram visitadas com o objetivo de analisá-las e combinar os detalhes do processo de pesquisa.

Quanto à forma de abordagem do problema, este estudo caracteriza-se como qualitativo e quantitativo. Na etapa qualitativa, a pesquisadora seguiu a orientação de Yin (2010), que recomenda a triangulação de dados por meio de entrevista semiestruturada, observação não participante e pesquisa documental. A triangulação é um processo de comparação de dados advindos de fontes diferencia- das, o que torna o estudo mais robusto e confiável, de acordo com Prodanov \& Freitas (2013).

$\mathrm{O}$ roteiro de entrevista, considerado por Yin (2010) como fonte essencial de evidências em estudos de caso, foi estruturado com base no referencial teórico selecionado e foi dividido em três blocos distintos. No primeiro bloco, foram apresentadas questões relacionadas ao diagnóstico ambiental do processo de produção, no qual se encontravam questões como: Quais são os recursos (input) utilizados no processo de produção? Quais são as saídas (output) geradas ao longo do processo? Qual o tratamento realizado com essas saídas? entre outras. Depois, abordou-se o detalhamento da dimensão social. Para isso, foram levados em consideração aspectos relacionados a ações realizadas pela empresa para atender os interesses de seus principais stakeholders. E, por último, foram apresentadas questões relacionadas à dimensão econômica, no qual aspectos relacionados à redução de custos e ganhos de receitas foram os pontos norteadores. Vale destacar que o roteiro de entrevista foi previamente validado por três experts, todos doutores e pesquisadores das áreas de Ciências Ambientais e Ciências Sociais Aplicadas. Além disso, o questionário também passou por pré-testes com profissionais da área de gestão da produção e gestores financeiros.

Tanto para as entrevistas quanto para a observação não participante, foram realizadas duas visitas às empresas participantes do estudo, nos meses de janeiro e fevereiro de 2016. Essas visitas foram guiadas pelos gerentes das organizações, que explicaram de forma detalhada todo o processo de produção do suco de uva orgânico. As visitas foram agendadas para esse período porque a produção do suco de uva orgânico nas empresas pesquisadas é 
realizado durante esses meses, em função da safra da uva ser anual.

A observação não participante, para Prodanov \& Freitas (2013), é uma técnica em que o pesquisador toma contato com o campo de estudo, porém permanece de fora, ou seja, sem integrar-se. Para essa fase, foi elaborado um roteiro contendo um total de 11 questões, com o objetivo de direcionar a pesquisadora durante as visitas nas organizações. Esse roteiro continha questões relacionadas à geração de resíduos e efluentes- ao seu destino ou tratamento-, ao controle do consumo de água e de energia, à capacitação dos colaboradores, entre outras.

Para complementar a análise dos dados da etapa qualitativa, foi realizada uma pesquisa em documentos que ainda não tinham recebido tratamento analítico. Para Yin (2010), essa fase é marcada pela análise de documentos administrativos, como propostas, relatórios e documentos internos organizacionais. Nesse sentido, o levantamento documental deu-se por meio de dados contábeis, atas de reuniões, sites das empresas e relatórios técnicos.

Os dados empíricos obtidos na etapa qualitativa foram submetidos à análise de conteúdo e divididos em 13 categorias de análise para as dimensões ambiental e econômica. Para a dimensão social da sustentabilidade, os dados foram analisados por meio de quatro categorias distintas (Silva, 2006; Bardin, 2011). Os resultados empíricos apresentados por pelo menos duas das três empresas participantes do estudo, e que são sustentados pelo suporte teórico, estão listados nas Tabelas 1, 2 e 3. Até essa etapa, os indicadores de sustentabilidade foram identificados por meio da revisão da literatura, mas posteriormente passaram por um filtro baseado em dados obtidos através das entrevistas, da observação não participante e da pesquisa documental. Um total de 31 indicadores de sustentabilidade pré-definidos para o processo foram escolhidos, distribuídos em ambiental (10), social (9) e econômico (12).

$\mathrm{Na}$ terceira e última fase, realizou-se uma abordagem quantitativa que, para Prodanov \& Freitas (2013), consiste em traduzir em números as informações para, posteriormente, organizá-las e analisá-las. Sendo assim, para essa etapa, os indicadores de sustentabilidade encontrados na pesquisa bibliométrica realizada por Feil et al. (2015), juntamente com os indicadores selecionados na etapa qualitativa do estudo, foram organizados em um construto por meio de uma escala Likert de 5 pontos, o qual passou por um teste piloto utilizando-se uma amostra, escolhida por conveniência e acessibilidade, do universo delimitado para a pesquisa. Segundo Robertson (2012), escalas Likert são utilizadas para identificar a opinião dos entrevistados por meio de uma escala. Aliada a uma análise estatística adequada, ela possibilita a identificação do posicionamento da grande maioria perante uma variável avaliada.

O constructo foi encaminhado para as organizações participantes do estudo. Obteve-se o retorno de quatro colaboradores de cada uma das organizações, totalizando 12 respostas. Os dados foram organizados em tabelas separadas, com a ajuda do Microsoft Excel 2010, de acordo com cada dimensão da sustentabilidade, com cálculos de média para todos os indicadores em todas as respostas. Posteriormente, os indicadores de sustentabilidade foram ranqueados da maior para a menor média.

Para o conjunto final, permaneceram apenas os indicadores que estavam presentes no primeiro quartil de cada tabela e que foram considerados relevantes para o setor. Como ponto de corte para as dimensões ambiental e social, utilizou-se uma 
média igual ou maior que 4,29 e, para a dimensão econômica, maior ou igual a 4,1. Dessa forma, para o conjunto final de indicadores para o processo produtivo do suco de uva orgânico, 22 indicadores distribuídos em ambiental (9), econômico (5) e social (8) foram selecionados.

\section{Resultados e discussões}

\subsection{Discussão e resultados da evidenciação empírica}

Os resultados obtidos na etapa qualitativa do estudo foram separados e organizados em três tabelas distintas, nas quais se apresentam as categorias de análises, as evidências empíricas coletadas e o suporte teórico encontrado. A opção da estruturação do artigo desse modo é proporcionar acesso a um número máximo de resultados de forma fácil, prática e didática. A Tabela 1 mostra a dimensão ambiental da sustentabilidade, a Tabela 2 a dimensão econômica e, por fim, a dimensão social é mostrada na Tabela 3.

\subsubsection{Dimensão ambiental da sustentabilidade}

A dimensão ambiental da sustentabilidade é caracterizada, principalmente, por recursos naturais e impactos ao ecossistema que são - ou podem ser ocasionados pelas atividades organizacionais, incluindo aspectos bióticos e abióticos (GRI, 2013). Para Callado (2010, p. 33), "os impactos ocorrem através do uso da terra, uso de recursos, de emissões de poluentes na atmosfera, água, terra e através do ciclo de vida de um produto". Ela também trata da preocupação relativa à preservação por meio da redução da poluição ambiental, seja através da produção de recursos renováveis ou da redução de resíduos descartados, reutilizando ou reciclando-os (Van Bellen, 2006; Delai \& Takahashi, 2008).

A partir da abordagem qualitativa do estudo, foi possível identificar alguns pontos-chave com relação à fabricação do suco de uva bordô orgânico, os quais estão destacados na Tabela 1 para a dimensão ambiental da sustentabilidade.

Considera-se sistema orgânico de produção aquele em que se adotam práticas específicas para otimizar o uso dos recursos naturais e socioeconômicos disponíveis no local. Essa produção tem por objetivo alcançar a sustentabilidade por meio do seu tripé (social, econômico e ambiental), minimizando as dependências em energia não renovável, e sempre que possível empregando métodos "biológicos, em contraposição ao uso de materiais sintéticos, organismos geneticamente modificados e radiações ionizantes, em qualquer fase do processo de produção", para atingir rendimentos adequados, manter o solo saudável, evitar erosões, realizar controle de pragas e reduzir a perda de biodiversidade presente naquele espaço (Brasil, 2003, p. 2). Essas características são evidenciadas nos dados empíricos, especialmente em relação ao cultivo da uva, de acordo com a Tabela 1 (Cruz et al., 2010; Souza et al., 2012; Alencar, et al., 2013; Falcão et al., 2013; Ilic et al., 2014).

Por possuírem o conceito de sustentabilidade, quando os produtos orgânicos são processados, eles precisam manter o mesmo ideal. Para a produção de 1.000 litros de suco de uva orgânico, sem adição e/ou mistura com outras variedades de uva, são 
TABELA 1 - Categorias de análise para a dimensão ambiental do processo produtivo do suco de uva orgânico.

Categorias de Análise

Categorias de Análise

Evidências Empíricas
Autores (Análise)

- Não utilização de materiais sintéticos;

- Não utilização de organismos geneticamente modificados;

- Não utilização de agrotóxico;

- Respeito ao ciclo de vida da fruta e do solo;

- Solo trabalhado com a enxada (resgate da cultura dos primeiros imigrantes italianos);

- Análise do solo;

Cultivo de uva - Utilização de fertilizantes orgânicos (adubação verde);

- Controle de pragas;

- Utilização de Uva bordô (melhor adaptação às condições de clima

e solo da região);

- Conservação da flora e fauna local;

- Safra anual;

- Certificação Orgânica;

- Rigoroso controle de maturação da uva;

Transporte da uva para a empresa
- Caixas plásticas específicas que facilitam o controle, o manuseio e a higienização, e que após sua utilização são encaminhadas novamente aos fornecedores para reutilização;
Brasil (2003), Assis \& Romeiro (2007), Cruz et al. (2010), Souza et al. (2012), Azevedo (2012), Alencar et al. (2013), Falcão et al. (2013), Ilic et al. (2014).
Delai \& Takahashi (2008), Rocha et al. (2013).

- Todo o processo realizado por meio de declividade;

- Sem adição e/ou mistura com outras variedades de uva;

Processamento da uva

- Caldeira a lenha com consumo diário de 3 metros cúbicos/dia;

- Gás Natural;

- Separação de engaço, casca e sementes da uva para posterior

Sachs (1993), Azapagic \& Perdan (2000), Krajnc \& Glavic (2003), destino;

- Máquinas de última geração que evitam, ao máximo, o desperdício, e que consomem menos energia (europeu);

- Manutenção sempre que necessário;

- Limpeza sempre que as máquinas são utilizadas;
Delai \& Takahashi (2008), Rocha et al. (2013).
- Os funcionários são capacitados através de treinamentos interno sobre "Boas Práticas de Fabricação" e "Manejo de Resíduos" uma vez por ano (conscientização);

- Todos os treinamentos são ministrados por profissionais da área,

Pessoas na produção como Biólogos, Engenheiros de Alimentos ou Nutricionistas, e que são funcionários das organizações;

- Todas as empresas possuem profissionais de diversas áreas atuando de forma ativa durante a produção, tais como: biólogos, enólogos, engenheiros, nutricionistas, administradores, entre outros;
Callens \& Tyteca (1999), Donaire (1999), Azapagic (2003), Richartz et al. (2009), Staniskis \& Arbaciauskas (2009), Orth et al. (2014). 
- A água da chuva é utilizada para lavagem externa (lavagem de calçadas e de veículos e para a descarga nos banheiros) e irrigação de hortas orgânicas presentes nas empresas;

- Para a higienização dos equipamentos, pisos, paredes e caixas

Atividades de limpeza plásticas utilizadas para o transporte de uva, enxague e resfriamento das garrafas, banheiros e pias em geral é utilizada água de poço artesiano.

- A cada seis meses é realizada análise microbiológica, e uma vez ao ano é realizada análise completa (físico-química e microbiológica). As análises são realizadas em laboratório terceirizado;

- Água de poço para resfriamento de garrafas;

- Reaproveitamento da água;

Envase

-Máquinas modernas que evitam o desperdício;

- Não tem adição de água ou conservantes;

- Transporte com redução de peso de carga;

Logística externa - Frota com tecnologia moderna que reduz emissões de gases;

- Rastreamento de veículos;

- Foco no consumidor local, evitando grandes deslocamentos;

Materiais auxiliares utili-
zados na produção

- Bombonas reutilizadas para separação de resíduos,

- Reaproveitamento de peças de outras indústrias;

- Lonas plásticas reutilizadas;

- Empresas localizadas em meio à natureza, arborizadas e cercada por parreirais;

- Cercadas por postes reutilizados de canos galvanizados;

- Muros de contenção com aproveitamento de blocos de concreteiras;

- Blocos de concreteiras reaproveitados para pavimentação das empresas;

Paisagismo

- Portas e janelas internas reutilizadas;

- Construção de móveis internos por meio de madeira de antigas

pipas;

- Ventilação natural;

- Iluminação natural através de telhas transparentes e vidros reutilizados;

-Hortas orgânicas;

- As cascas e as sementes de uvas geradas ao longo do processo produtivo do suco de uva são aproveitadas na composição de outros produtos;

- O engaço e restos de bagaço são incorporados ao solo, em área distante de cursos de água, e dispersos de forma a impossibilitar o seu arraste por ocasião de chuvas;

Gestão de resíduos da produção
- Os resíduos de plástico, papel e papelão são comercializados para indústrias de reciclagem ou são doados para os fornecedores de uva;

- Os resíduos de vidro acumulados em bombonas localizadas em ambiente separado da área de produção também são comercializados para indústrias de reciclagem;

- Compostagem orgânica;
Azapagic \& Perdan (2000), Corazza (2003), Nordheim \& Barrasso (2007), Staniskis \& Arbaciauskas (2009), Cavalcante et al. (2013), Linke et al. (2013).

Delai \& Takahashi (2008),

Staniskis \& Arbaciauskas (2009), Rocha et al. (2013).

Callens \& Tyteca (1999), Erol et al. (2009).

Corazza (2003), Delai \&

Takahashi (2008), Erol et al.

(2009), Rocha et al. (2013).
Delai \& Takahashi (2008), Rocha et al. (2013).
Sachs (1993), Callens \& Tyteca (1999), Greiner (2001), Azapagic (2003), Corazza (2003), Krajnc \& Glavic (2003), Delai \&

Takahashi (2008), Staniskis \& Arbaciauskas (2009),Erol et al. (2009), Kinderyte (2010), Tokos et al. (2012), Rocha et al. (2013), Santos et al. (2014). 
- Utilização de rótulos ecológicos;

- Garrafas ecológicas, que chegam a pesar $22 \%$ a menos que uma garrafa comum, gerando menos material e redução no consumo energético e transporte;

Manuseio e tratamento de embalagens

- Cobertura de lonas plásticas reutilizadas;

-Embalagens a vácuo;

- Embalagens de papelão recicladas;

- Os efluentes líquidos são tratados no lugar e são absorvidos pelo

Tratamento de efluentes solo. Os padrões de emissão adotados são os exigidos pela Licença de Operação, emitida pela Fepam.

Delai \& Takahashi (2008), Azevedo (2012), Curi (2012), Rocha et al. (2013).

Archela et al. (2003), Azapagic

(2003), Kinderyte (2010).

FONTE: Os autores.

os seguintes recursos: aproximadamente $35 \mathrm{Kw}$ de energia elétrica; 250 litros de água (somente para a higienização); $1.300 \mathrm{Kg}$ de uva orgânica (aquisição através de propriedades familiares localizadas nos municípios da região) e $100 \mathrm{ml}$ de enzimas (garantem sabor, aroma e cor ao suco).

A utilização de água e energia é considerada crucial para o processo produtivo (Azapagic \& Perdan, 2000; Seuring et al., 2003; Corazza, 2003; Delai \& Takahashi, 2008; Cavalcante et al., 2013). Costa (2010) destaca que a água não é um recurso que existe de forma ilimitada na natureza, e que ela é essencial para todos os tipos de processos que sustentam as formas de vida na Terra. Além de ser um importante componente do organismo humano, ela é matéria-prima dos processos produtivos, gera energia e faz parte do ciclo produtivo vegetal, entreoutras funções (Carvalho et al., 2012). Para Strasburg \& Jahno (2015), a água é um recurso fundamental para a produção de alimentos, apesar de forma direta, sendo utilizada em outras etapas, como na higiene do ambiente, na limpeza de embalagens e equipamentos, no arrefecimento/aquecimento, como solvente de reação, entre outros (Cavalcante et al., 2013; Linke et al., 2013). Dessa forma, controlar e proteger esse recurso é de muitas vezes não ser incorporada no processo essencial para a vida de- vido aos diversos usos a que ele se destina. Nas empresas estudadas, esse recurso não é utilizado de forma direta na composição do suco de uva orgânico, no entanto, ele está presente principalmente nas atividades de limpeza e higienização, bem como na etapa de envase. Para isso, as empresas utilizam água de poço artesiano e, também, buscam aproveitar água da chuva, como pode ser verificado na Tabela 1.

Com relação à energia, para Krajnc \& Glavic (2003), a indústria é uma grande consumidora de energias não renováveis, as quais causam danos diretos ao meio ambiente. Krajnc \& Glavic (2003) e Delai \& Takahashi (2008) destacam a importância da utilização de energias renováveis, como a solar,a eólica e a biomassa, pois são fontes redutoras de impactos negativos ao meio ambiente, e contribuem para o alcance da sustentabilidade do processo produtivo. Sachs (1993) corrobora com essa ideia,salientando a importância da diminuição do uso de energias não renováveis, substituindo-as pelas renováveis. Nesse sentido, itens como iluminação natural, caldeira a lenha e gás natural, são algumas alternativas encontradas pelas empresas estudadas, a fim de reduzir o consumo de energia não renovável, como pode ser visto na Tabela 1 . De forma complementar, tais medidas contribuem 
para a redução de custos, abraçando, dessa forma, a dimensão econômica da sustentabilidade.

Além de entradas identificadas ao longo do processo, toda transformação de recursos em produto final ocasiona saídas (Harrington, 1993; Andersen, 1999), sendo elas: 250 litros de efluentes líquidos e $5.000 \mathrm{Kg}$ de resíduos do engaço da uva (as empresas não possuem controle para cada 1.000 litros de suco produzido). Além disso, também são encontrados ao longo do processo resíduos como: papel, papelão, plástico, vidro e alumínio, assim como cascas, engaços e sementes gerados da própria fruta.

Os resíduos sólidos são considerados, atualmente, um dos principais problemas ambientais da humanidade (Callens \& Tyteca, 1999; Azapagic, 2003; Orth et al., 2014). Santos et al. (2014) comentam que isso se deve ao crescimento gradativo e desordenado da população, bem como à descartabilidade acentuada de produtos pela sociedade. A utilização de resíduos na composição de novos produtos pode ser uma alternativa para o seu reaproveitamento (Sachs, 1993). Para Estrela (1996), ao reutilizar-se o material que antes seria encaminhado para o aterro, otimiza-se a relação entre energia, meio ambiente, e materiais, o que proporciona um aproveitamento maior do resíduo ou do gasto energético envolvido. Delai \& Takahashi (2008), Staniskis \& Arbaciauskas (2009), Tokos et al. (2012) e Rocha et al. (2013) concordam com esse apontamento, enfatizando a importância da eficiência no uso de materiais, o que implica de forma concreta na redução de resíduos. Entretanto, para esse processo é necessário, por parte da organização, alto nível de tecnologia e de desenvolvimento do produto, a fim de proporcionar resultados satisfatórios na composição de novos produtos (Erol et al., 2009; Kinderyte, 2010). Para isso, as empresas contam com equipe multidisciplinar e parcerias institucionais, nas quais estudos foram desenvolvidos para que a casca e a semente fossem reutilizadas na composição de novos produtos que também fossem certificados organicamente, a fim de continuar atingindo seu público-alvo. Dessa forma, as empresas conseguem otimizar o gasto envolvido na composição do produto, evitam o encaminhamento de resíduos a aterros, além de conseguirem gerar receitas com as vendas dos novos produtos.

A reciclagem também é uma das alternativas encontradas para a redução dos impactos negativos ao meio ambiente, relacionados ao acumulo de resíduos (Greiner, 2001; Krajnc \& Glavic, 2003). Ela reduz a demanda por espaços nos aterros industriais e, principalmente, evita o desperdício de algum material que possa ser utilizado em outro ambiente (Santos et al., 2014). Nas três empresas pesquisadas, todos os resíduos gerados que não são reutilizados dentro das organizações são comercializados para indústrias de reciclagem, ou são doados para os fornecedores de uva para o seu reaproveitamento ou reciclagem, como destacado na Tabela 1.

Richartz et al. (2009) afirmam que, para geren ciar melhor essas questões, exige-se conhecimento acerca da empresa e dos impactos ambientais ocasionados por ela, e uma equipe multidisciplinar pode proporcionar isso. Quando diferentes profissionais trabalham em conjunto, as tarefas são desenvolvidas em menos tempo e com qualidade, a produtividade aumenta, e a empresa se desenvolve. Orth et al. (2014) consideram a educação ambiental como alicerce para o sucesso das medidas vinculadas a redução dos impactos ambientais, o qual pode ser alcançado por meio de palestras, treinamentos, capacitações, oficinas, ou outras formas. Os autores 
destacam ainda a importância das atividades serem ministradas por pessoas qualificadas, mas que preferencialmente sejam funcionários que tenham conhecimento sobre o meio ambiente e atuem diretamente nas questões ambientais da empresa, e que o programa não abranja mais que três temas diferenciados, de forma a não dificultar o processo de ensino/aprendizado (Donaire, 1999). Vale destacar que, nas empresas estudadas, todos os funcionários vinculados, principalmente, ao setor de produção, recebem treinamentos em "Boas Práticas de Fabricação" e "Manejo de Resíduos", desenvolvidos pelos funcionários internos.

\subsubsection{Dimensão econômica da sustentabilidade}

A dimensão econômica da sustentabilidade está relacionada aos impactos (em curso ou potenciais) no sistema econômico local, nacional e global (Labuschagne et al., 2005; GRI, 2013). A sustentabilidade econômica está vinculada a fluxos regulares de investimentos e a uma gestão eficiente de recursos, no qual a redução de custos e a geração de receitas são fundamentais (Sachs, 1993; Azapagic \& Perdan, 2000). Além disso, ela trata da diversificação das atividades produtivas e da atualização de instrumentos de produção por meio de acesso à ciência e à tecnologia (Azapgic, 2003; Krajnc \& Glavic, 2005; Savitz \& Weber, 2006; GRI, 2013). Callado (2010) destaca que, por mais que o desempenho econômico seja apresentado por diversos autores como sendo a dimensão mais importante dentro do conceito de sustentabilidade empresarial, essa abordagem não pode assumir maior relevância perante as outras.
Devido à pequena oferta dos produtos orgânicos, mesmo que esse mercado esteja em constante crescimento, os consumidores ainda pagam valores mais elevados em comparação a produtos convencionais. Lotter (2003) destaca que os rendimentos dos produtos orgânicos são, em média, 10 a 15\% menores do que os dos convencionais, porém esses valores são compensados pela redução nos custos de produção, como pode ser verificado na parte "Cultivo de uva", na Tabela 2, e pela margem bruta mais elevada. Para o MAPA (2015), os produtos orgânicos agregam em média $30 \%$ a mais quando comparado aos produtos convencionais, devido a diversas variáveis como: gerenciamento da unidade de produção, canal de comercialização, oferta e demanda dos produtos, menor escala de produção, custos para o reconhecimento de qualidade orgânica, entre outras. No entanto, apesar do preço ser uma das principais desvantagens do produto orgânico, Dias et al. (2015) destaca que esse mercado continua com expressivas taxas de crescimento justamente por proporcionar características de "produto com valor agregado", ou seja, os consumidores pagam não apenas pelo produto, mas também pelos ben fícios que ele proporciona. Para North (1997), umanova demanda por produtos ecologicamente corretos está em ascensão, principalmente pela busca por produtos favoráveis à saúde e ao meio ambiente, o que contribui para o impulso desse mercado.

O desenvolvimento de pesquisas na área de orgânicos pode fazer com que esses números cresçam, como é o caso das empresas estudadas. Todas elas possuem vínculo com universidades do Estado do Rio Grande do Sul, nas quais são desenvolvidas dissertações de mestrado e teses de doutorado, e também projetos de pesquisa com foco em inova- 
TABELA 2 - Categorias de análise para a dimensão econômica do processo produtivo do suco de uva orgânico.

Categorias de Análises

\begin{tabular}{|c|c|c|}
\hline Cultivo da Uva & $\begin{array}{l}\text { - Não utilização de materiais sintéticos; } \\
\text { - Não utilização de organismos geneticamente modificados; } \\
\text { - Não utilização de agrotóxico; } \\
\text { - Respeito ao ciclo de vida da fruta e do solo; } \\
\text { - Solo trabalhado com a enxada (resgate da cultura dos primeiros } \\
\text { imigrantes italianos); } \\
\text { - Utilização de fertilizantes orgânicos (adubação verde); } \\
\text { - Possibilidades de visitas técnicas; } \\
\text { - Certificação orgânica; }\end{array}$ & $\begin{array}{l}\text { Brasil (2003), Lotter (2003), } \\
\text { Assis \& Romeiro (2007), } \\
\text { Cruz et al. (2010), Souza et } \\
\text { al. (2012), Azevedo (2012), } \\
\text { Alencar et al. (2013), Falcão } \\
\text { et al. (2013), Ilic et al. } \\
\text { (2014). }\end{array}$ \\
\hline Transporte da uva para a empresa & - Caixas plásticas reutilizadas; & $\begin{array}{l}\text { Delai \& Takahashi (2008), } \\
\text { Rocha et al. (2013). }\end{array}$ \\
\hline Processamento da uva & $\begin{array}{l}\text { - Declividade; } \\
\text { - Certificação orgânica; } \\
\text { - Possibilidades de visitas técnicas; } \\
\text { - Caldeira a lenha com consumo diário de } 3 \text { metros cúbicos/dia; } \\
\text { - Luz natural; }\end{array}$ & $\begin{array}{l}\text { Sachs (1993), Azapagic } \\
\& \text { Perdan (2000), Krajnc } \\
\text { \& Glavic (2003), Delai \& } \\
\text { Takahashi (2008). }\end{array}$ \\
\hline Pessoas na Produção & $\begin{array}{l}\text { - Treinamento e desenvolvimento pelos próprios colaboradores } \\
\text { internos e capacitados; } \\
\text { - Profissionais de diversas áreas; } \\
\text { - Assinatura da Carteira de Trabalho; }\end{array}$ & $\begin{array}{l}\text { Donaire (1999), Azapagic } \\
\text { (2003), Richartz et al. (2009), } \\
\text { Orth et al. }(2014) \text {. }\end{array}$ \\
\hline Atividades de Limpeza & $\begin{array}{l}\text { - Utilização de água da chuva e poço artesiano para higienização de } \\
\text { diversos ambientes; }\end{array}$ & $\begin{array}{l}\text { Donaire (1999), Corazza } \\
\text { (2003). }\end{array}$ \\
\hline Envase & $\begin{array}{l}\text { - Uso de água de poço para resfriamento de garrafas; } \\
\text { - Reaproveitamento da água; } \\
\text {-Máquinas modernas que evitam o desperdício; } \\
\text { - Sem adição de água ou conservantes ao produto; } \\
\text { - Luz natural; }\end{array}$ & $\begin{array}{l}\text { Delai \& Takahashi (2008), } \\
\text { Staniskis \& Arbaciauskas } \\
\text { (2009), Rocha et al. (2013). }\end{array}$ \\
\hline Paisagismo & $\begin{array}{l}\text { - Visitas Técnicas; } \\
\text { - Atividades vinculadas ao turismo ecológico e turismo rural; } \\
\text { - Programas de Educação Ambiental; }\end{array}$ & $\begin{array}{l}\text { Benitez \& Golinski (2007), } \\
\text { Azevedo (2012), Curi (2012). }\end{array}$ \\
\hline Gestão de Resíduos na Produção & $\begin{array}{l}\text { - Desenvolvimento de produtos verdes a partir de resíduos (certifica- } \\
\text { dos); (farinha, óleo, azeite, suco, vinhos, espumantes); } \\
\text { - Possibilidades de venda ao mercado internacional; } \\
\text { - Apoio e auxílio em projetos de pesquisa, dissertações e teses de } \\
\text { doutorado; }\end{array}$ & $\begin{array}{l}\text { Clark \& Fujimoto (1991), } \\
\text { Sanchs (1993), North (1997), } \\
\text { Donaire (1999), Delai \& } \\
\text { Takahashi (2008), Rocha et } \\
\text { al. (2013), Theis \& Schreiber } \\
\text { (2015). }\end{array}$ \\
\hline
\end{tabular}


- Todos os resíduos são separados internamente pelos próprios

colaboradores;

- Resíduos encaminhados para reciclagem;

- Resíduos doados para fornecedores de uva;

- Possibilidades de visitas técnicas;

\begin{tabular}{lll}
\hline $\begin{array}{l}\text { Manuseio e tratamento de emba- } \\
\text { lagens }\end{array}$ & - Compras programadas de garrafas de vidro novas; & $\begin{array}{l}\text { Delai \& Takahashi (2008), } \\
\text { Azevedo (2012), Curi (2012), } \\
\text { Rocha et al. (2013). }\end{array}$ \\
\hline Tratamento de Efluentes & - Realizado internamente; & $\begin{array}{l}\text { Archela et al. (2003), Azapa- } \\
\text { gic (2003), Kinderyte (2010). }\end{array}$ \\
\hline
\end{tabular}

FONTE: Os autores.

ção, pesquisa e desenvolvimento na área. De acordo com as organizações estudadas, estabelecer parcerias entre universidades e empresas é uma grande oportunidade de se manterem atualizadas e competitivas no mercado, pois isso colabora diretamente para soluções de problemas encontrados, bem como contribui para a divulgação dos produtos em grande escala. As empresas ainda destacam que algumas inovações, como reutilização de resíduos na composição de novos produtos, utilização de gás natural, aproveitamento de água da chuva em algumas etapas do processo produtivo, tratamento de efluentes internamente, bem como a abertura das empresas para visitas técnicas e possibilidades de turismo rural e ecológico, não poderiam ter sido concretizadas sem as parcerias firmadas. Essas medidas contribuem inteiramente para a redução de custos e geração de receita, assim como proporcionam a divulgação em escala maior das organizações.

Além disso, as empresas ressaltaram a importância da participação em feiras, seminários e congressos, tanto nacionais como internacionais, por exemplo, a Bio Brazil Fair ${ }^{1}$, com o objetivo de estar sempre buscando oportunidades diferenciadas Para Theis \& Schreiber (2015), essas parcerias podem contribuir para o desenvolvimento de novos mercados ou consolidar os já atuantes, proporcionando soluções mais concretas para os consumidores. Além do suco de uva orgânico, todas as organizações pesquisadas comercializam outros produtos: vinhos, espumantes, frisantes, molhos comestíveis, farinha de casca de uva, farinha de semente de uva, óleo de semente de uva e vinagres. Vale destacar que muitos deles são originados de resíduos provenientes do suco de uva orgânico, desenvolvidos a partir de estudos em parceria com Instituições de Ensino Superior. North (1997) destaca que ganhos econômicos podem ser obtidos com a inovação de produtos oriundos dos resíduos do processo produtivo, e que a redução de custos com materiais novos, com processamento e com descarte também podem ser identificados (Delai \& Takahashi, 2008; Rocha et al., 2013). Quando os investimentos estão vinculados à pesquisa e ao desenvolvimento, isso demonstra preocupação por parte das organizações em se manterem competitivas, pois novos produtos podem ser inseridos no mercado, incrementando, dessa forma, a produtividade e consequentemente a receita organizacional (Clark \& Fujimoto, 1991). Novos investimentos são essenciais para prover

${ }^{1}$ Feira Internacional de Produtos Orgânicos e Agroecologia. É considerado o maior evento de negócios de produtos orgânicos da América Latina. http://www.biobrazilfair.com.br/2017/index.asp. 
à empresa os recursos necessários para seu crescimento, bem como para a renovação de ativos a fim de garantir a lucratividade a longo prazo, como destacam Fiksel et al. (1998), Delai \& Takahashi (2008) e Callado (2010).

Nas empresas estudadas, os sucos de uva bordô orgânicos são envasados por meio de máquinas consideradas pelos gerentes como "modernas" e de "última geração". Isso só foi possível porque foram realizados altos investimentos a fim de reduzir ao máximo o desperdício e, dessa forma, aumentar a produtividade. "Produtividade é um índice que mede a relação entre output gerado (bem produzido ou serviço executado) e o input (mão de obra, materiais, energia e outros recursos) para produzir aquele output" (Stevenson, 2001, p. 24). Nesse sentido, ela é uma medida de efetividade da utilização dos recursos, ou seja, é utilizada para avaliar o desempenho do processo produtivo. De forma complementar, as empresas contam ainda com um sistema de controle operacional interno, apresentando os dados por meio de planilhas e gráficos para posterior análise em relação aos resultados do processo produtivo. De acordo com Wildauer \& Wildauer (2015), o crescimento econômico de uma organização pode ser expresso pela combinação do aumento de insumos de entrada no processo produtivo e do aumento na produtividade.

Outra possibilidade de alavancar ganhos, vinculados à inserção da variável ambiental dentro das empresas, são as possibilidades de turismo ecológico, turismo rural e também programas de educação ambiental e visitas técnicas, medidas essas identificadas nas empresas estudadas, como é possível ver na Tabela 2, na categoria "Paisagismo" (Benitez \& Golinski, 2007). Ações desse tipo conferem legitimidade e reconhecimento por parte da sociedade. Jabbour et al. (2009) e Souza (2012) complementam que esse processo impacta os stakeholders com mais intensidade, visto que permite a demonstração pública da empresa, ou seja, maior visibilidade à responsabilidade socioambiental da empresa.

A certificação orgânica encontrada em todas as empresas também confere status de empresa amiga do meio ambiente (Jabbour et al., 2009; Souza, 2012; ISO, 2016). Para Azevedo (2012) e Curi (2012), os selos de qualidade conferem à empresa credibilidade em relação ao produto e conquistam a confiança do cliente. Entretanto, vale ressaltar que, por possuírem o selo de certificação de orgânicos, essas empresas recebem visitas periódicas (auditorias) da certificadora, que exige adaptações com relação ao processo produtivo, às embalagens e à distribuição, o que em um primeiro momento pode gerar despesas operacionais. De acordo com Muñoz et al. (2016), a certificação por auditorias implica custos elevados e sofre influência de diversos fatores, como tamanho da área a ser certificada, elaboração de relatórios, análises laboratoriais, visitas, entre outros. "A auditoria trata-se de um instrumento empregado pelas empresas com o objetivo de auxiliar no atendimento à política, às práticas, aos procedimentos e aos requisitos legais, além de minimizar ou anular os impactos ambientais gerados" (Mazzarotto \& Berté, 2013, p. 33).

\subsubsection{Dimensão social da sustentabilidade}

A dimensão social caracteriza-se pelas condições e pelas mudanças nos sistemas sociais em que uma empresa atua (GRI, 2013). Para Callado (2010, p. 37), “esta dimensão inclui estratégias de 
proteção para reduzir a vulnerabilidade, melhorar a equidade e assegurar que as necessidades básicas de uma sociedade sejam atendidas". A dimensão social trata de melhorias no bem-estar individual e coletivo, valorizando as características particulares de cada ser humano. Essa dimensão abrange também aspectos relacionados a práticas éticas no ambiente de trabalho e melhorias no ambiente organizacional (Azapagic \& Perdan, 2000; Azapgic, 2003; Claro \& Claro 2004; Krajnc \& Glavic, 2005; Savitz \& Weber, 2006; GRI, 2013).

$\mathrm{Na}$ etapa qualitativa do estudo, foi possível perceber que as empresas estudadas possuem ações particulares com o objetivo de atender seus principais stakeholders. As categorias de análise para esta dimensão estão especificadas na Tabela 3, na qual também se são destacadas as evidências empíricas encontradas.

A tabela proposta para a dimensão social da sustentabilidade mostra as iniciativas que as empresas tomam a respeito dos sistemas sociais em que operam, bem como o relacionamento das empresas com suas várias partes interessadas (Labuschagne et al., 2005).

As melhorias internas estão centradas nos funcionários, com os quais as empresas possuem uma preocupação constante, porque desejam proporcionar um ambiente de trabalho saudável, seguro e ético para todos, o que Azapagic \& Perdan (2000), Labuschagne et al. (2005), Azapagic (2003) e Callado (2010) destacam ser de suma importância para qualquer negócio. Seuring et al. (2003), Nordheim \& Barrasso (2007) e Delai \& Takahashi (2008) afirmam que essas variáveis influenciam na produtividade dos funcionários, assim como em sua satisfação perante a atividade desenvolvida e a empresa com a qual estão vinculados. Para Do- naire (1999), o desempenho da organização está fortemente vinculado à qualidade de seus recursos humanos, ou seja, o quadro de colaboradores impacta diretamente nos resultados alcançados pela organização.

Além disso, bem-estar e estímulo a uma vida saudável também são questões identificadas e de preocupação constante com relação aos funcionários por parte das organizações, como pode ser visualizado na Tabela 3. Callado (2010) destaca que o desenvolvimento social está diretamente ligado a melhorias no bem-estar individual, mas também coletivo. Benitez \& Golinski (2007) destacam que, pela não utilização de agrotóxicos, os produtos orgânicos estão associados também a menores gastos com saúde, tanto do agricultor quanto dos colaboradores das empresas e dos consumidores.

Do ponto de vista externo, com relação aos consumidores, à comunidade e aos fornecedores, as organizações também devem possuir ações específicas com o objetivo de atender os interesses de cada um, conforme apontado por Claro \& Claro (2004) e Callado (2010). Com relação à comunidade e aos fornecedores, as empresas buscam valorizar os conhecimentos tradicionais das famílias, preservando os costumes e as práticas agrícolas usadas há muitos anos pelos agricultores. Para Karam (2001), a agricultura orgânica representa a manutenção do modo de vida do campo por meio da valorização dos conhecimentos do próprio agricultor. Benitez \& Golinsky (2007) e Azevedo (2012) destacam que a produção orgânica preserva a identidade cultural e as condições de saúde da família e/ou da comunidade envolvida no processo, principalmente, pelo não manuseio de agrotóxicos.

As famílias que ainda não possuem a prática do processo orgânico são incentivadas pelas empresas 
TABELA 3 - Categorias de análise para a dimensão social do processo produtivo do suco de uva orgânico.

\section{Categorias de} Análise

\section{Evidências Empíricas}

Autores (Análise)

\begin{tabular}{lll}
\hline & - Empresas familiares, com contratação de funcionários da comu- & \\
& nidade local; \\
& - Todos os funcionários recebem treinamentos e capacitações com & \\
& o objetivo de preservar sua integridade física; \\
& - Recursos Humanos especializado (profissionais de diversas & \\
& áreas, enólogos, nutricionistas, administradores, biólogos, enge- & Callens \& Tyteca (1999), Donaire \\
& nheiros); & (1999), Azapagic \& Perdan (2000), \\
& - Os funcionários desenvolvem suas atividades utilizando equi- & Greiner (2001), Azapagic (2003), \\
& pamentos de proteção individual (EPI) como: roupa adequada, & Krajnc \& Glavic (2003), Seuring \\
et al. (2003), Labuschagne et al. & (2005), Nordheim \& Barrasso (2007), \\
& - Funcionários em constante atualização (participação em eventos & Delai \& Takahashi (2008), Erol et \\
& nacionais e internacionais); & al. (2009), Staniskis \& Arbaciauskas \\
& - Todos os funcionários possuem Carteira de Trabalho Assinada, \\
& dessa forma as empresas garantem o pagamento correto de todos & (2009), Callado (2010), Kinderyte \\
& os direitos trabalhistas; & (2010), Li et al. (2012). \\
& - Disponibilidade de hospedagem junto às empresas, caso neces- & \\
& sário; & \\
& - Oferta de horta orgânica com frutas e verduras a disposição de & \\
& colaboradores; & \\
& - Refeitório local; & \\
& - Disponibilidade de sucos de uva para consumo; &
\end{tabular}

- Identificação da origem da uva, com data da colheita, o tipo de manejo orgânico e o teor de açúcar presente na fruta. Isso é realizado caso seja necessário um posterior rastreamento do produto final elaborado (garantir qualidade da uva);

- Os sucos são envasados a vácuo em garrafas de vidro que permitem a conservação do produto sem adição de conservantes e proporcionam proteção contra mudanças de cor, sabor e características nutricionais provocadas pela incidência de luz e calor (qualidade do produto);

- Produto sem adição de água e conservantes;

- Processo de produção rápido que garante a qualidade do produto (até 6 horas);

- Tampa do produto com trava de segurança;

- Estoque coberto, sem contato com o sol (qualidade do produto);

- Processo de análise residual (verificar a pureza do produto);

- Os funcionários participam constantemente de campanhas, programas de rádio e televisão divulgando hábitos saudáveis vinculados aos produtos orgânicos;

- Premiações relacionadas aos produtos;

- Oferta de produtos com valor nutricional alto e que preservam o meio ambiente;

- Todos os produtos são embalados com pesos padronizados, rotulados de acordo com a legislação e etiquetados com o selo ecológico (SisOrg);

- Dicas de receitas saudáveis com a utilização de produtos orgânicos;

- Todas as empresas recebem visitas periódicas de sua certificadora;
Greiner (2001), Krajnc \& Glavic (2003), Benitez \& Golinsky (2007), Erol et al. (2009), Azevedo (2012), Rizzon \& Miele (2012). 


\begin{tabular}{|c|c|c|}
\hline Comunidade & $\begin{array}{l}\text { - Possível agendamento de visitas técnicas; } \\
\text { - Desenvolvimento de pesquisas, teses e dissertações com foco na } \\
\text { região; } \\
\text { - Redução de resíduos provenientes do processo produtivo; } \\
\text { - Cumprimento com o pagamento de impostos; } \\
\text { - Eventos envolvendo a comunidade (Dia da Árvore; Dia do Colo- } \\
\text { no; Dia do Nutricionista); } \\
\text { - Palestras e assembleias sobre a educação ambiental; } \\
\text { - Distribuição de mudas de árvores; } \\
\text { - Emprego de técnicas orgânicas; }\end{array}$ & $\begin{array}{l}\text { Callens \& Tyteca (1999), Azapagic \& } \\
\text { Perdan (2000), Claro \& Claro (2004), } \\
\text { Erol et al. (2009), Kinderyte (2010). }\end{array}$ \\
\hline Fornecedores & $\begin{array}{l}\text { - Agricultura familiar (pequenos produtores); } \\
\text { - Fornecedores locais, certificados ou que possuam cadastro junto } \\
\text { ao MAPA; } \\
\text { - Todos os fornecedores de uva são remunerados com valores } \\
\text { acima do mercado; } \\
\text { - Todos os fornecedores de uva são acompanhados periodicamente } \\
\text { pelo gerente das organizações e também pela certificadora do } \\
\text { produto orgânico (apoio técnico à disposição durante o ano todo); } \\
\text { - Limpeza de Videiras e Colheita manual; } \\
\text { - Não utilização de fornecedores que apresentam suas proprieda- } \\
\text { des próximas à agricultura convencional; } \\
\text { - Projeto Via Orgânica (fortalecimento da agricultura orgânica } \\
\text { local); }\end{array}$ & $\begin{array}{l}\text { Azapagic \& Perdan (2000), Karam } \\
\text { (2001), Azapagic (2003), Benitez \& } \\
\text { Golinsky (2007), Azevedo (2012), Li } \\
\text { et al. }(2012) .\end{array}$ \\
\hline
\end{tabular}

FONTE: Os autores.

a aprendê-lo através da implantação desse novo processo, o que se propaga naturalmente aos vizinhos e conhecidos. Aumentar a produtividade por meio de incentivos que satisfaçam as necessidades locais, de acordo com Callens \& Tyteca (1999) e Azapagic \& Perdan (2000), é uma forma de valorizar a comunidade e se tornar sua parceira, tornando-a responsável, também, por esse espaço. Dessa forma, conforme Labuschagne et al. (2005), Erol et al. (2009), Kinderyte (2010) e Li et al. (2012), a empresa também contribui para o desenvolvimento econômico da sua localidade.

Com relação aos consumidores, as empresas procuram oferecer produtos de qualidade, divulgando e estimulando hábitos saudáveis. Uma forma de divulgação das práticas conduzidas nas propriedades foi a criação, em 2016, de uma das primeiras rotas de propriedades orgânicas certificadas do Brasil, denominada "Via Orgânica". O passeio esti- mula o consumo de produtos orgânicos, enfatizando suas principais diferenças em relação à agricultura convencional, Duas das três empresas participantes do estudo fazem parte dessa rota, na qual o visitante pode encontrar: belas paisagens, resgate de antigas formas de cultivo e processos de elaboração de produtos orgânicos aprimoradas pelas novas tecnologias, contato direto com a simplicidade, e a experiência de quem produz e prepara o alimento.

As mudanças de certas variáveis socioeconômicas, sentidas principalmente a partir da década de 1990, como renda, educação e informação, refletiram em transformações nos hábitos dos consumidores atuais, que demandam alimentos relacionados a valores e/ou à consciência sobre meio ambiente, sobre questões éticas, e de qualidade e saúde (Andrade \& Bertoldi, 2012). De acordo com Rizzon \& Miele (2012), a comercialização do suco de uva orgânico tem ganhado espaço no mercado 
devido, principalmente, a sua qualidade e aos valores nutricionais envolvidos. Para Azevedo (2012), os produtos orgânicos podem ser considerados mais saudáveis por causa da não utilização de agrotóxicos, mas também em função do cultivo em solos naturais, ricos em nutrientes. Além disso, os selos de qualidade apresentados pelos produtos orgânicos podem garantir a busca por produtos com esse apelo.

\subsection{Resultados da etapa quantitativa (Escala Likert de 5 pontos)}

Posterior à etapa quantitativa e qualitativa do estudo, chegou-se a um total de 22 indicadores de sustentabilidade, distribuídos em nove indicadores ambientais, cinco indicadores econômico e oito indicadores sociais. Dessa forma, a Tabela 4 demonstra o conjunto de indicadores de sustentabilidade selecionados para o processo produtivo de suco de uva orgânico nas três dimensões da sustentabilidade.

Adotar práticas sustentáveis, com foco nos aspectos ambientais, sociais e econômicos, tem sido o diferencial para as empresas preocupadas com a sustentabilidade empresarial e também com o desenvolvimento sustentável no longo prazo (Lee \& Saen, 2012). Para as agroindústrias pertencentes ao estudo em questão, a Tabela 4 representa uma ferramenta de gestão (conjunto de indicadores de sustentabilidade) capaz de realizar a avaliação de um determinado espaço, a fim de propor um conjunto de ações para a transformação do ambiente, ou seja, indicam um direcionamento para a implementação de ações corretivas em busca da sustentabilidade (Miranda \& Teixeira, 2004).

Do ponto de vista ambiental, para que o processo produtivo tenha características sustentáveis, é suficiente avaliar aspectos relacionados à água, à energia, e à geração e disposição de resíduos (inclusive a possibilidade de reciclagem), de acordo com os autores Corazza (2003) e Erol et al. (2009). Segundo Krajnc \& Glavic (2003), para o processo produtivo ser considerado sustentável do ponto de vista ambiental, ele precisa minimizar os impactos negativos ao meio ambiente, ou seja, deve trabalhar com a redução de matéria-prima oriunda de recursos naturais, além de reaproveitar, reciclar ou dispor de maneira correta os resíduos decorrentes do processo produtivo. Para Greiner (2001), o processo produtivo também deve ter eficiência energética e reduzir ao máximo o consumo de água. Dessa forma, os indicadores de sustentabilidade propostos para a dimensão ambiental do processo produtivo do suco de uva orgânico englobam todas as questões consideradas essenciais pelos diversos autores revisados dentro do estudo.

Por fim, Krajnc \& Glavic (2003), Erol et al. (2009) e Greiner (2001) consideram sustentável, do ponto de vista social, o processo produtivo que é seguro e saudável para os trabalhadores, para as comunidades e para os consumidores. Azapagic \& Perdan (2000), Azapagic (2003) e Labuschagne et al. (2005) corroboram com essa ideia, enfatizando que as empresas possuem responsabilidades não apenas com os colaboradores envolvidos diretamente no desenvolvimento das atividades, mas também com a comunidade em que estão inseridas e com a sociedade de forma geral. Dessa forma, os indicadores sociais passam a envolver todos que de alguma forma são impactados com o processo de produção do suco de uva. 
TABELA 4 - Indicadores de sustentabilidade para a produção de suco de uva orgânico

\begin{tabular}{lcc}
\hline \multicolumn{1}{c}{ Ambiental } & Econômico & Social \\
\hline Certificação Ambiental & Custos Operacionais e Despesas & Apoio a Comunidades Locais \\
Quantidade de água utilizada & Gastos com Auditorias & Estímulo a uma vida saudável \\
Desenvolvimento de produtos verdes & Novos investimentos & Ética Organizacional \\
Efluentes Líquidos & Pesquisa e Desenvolvimento & Preservação dos Valores Culturais \\
Impactos Ambientais & Produtividade & Propagação das Práticas Orgânicas \\
Resíduos Sólidos & & Qualidade do Produto \\
Reuso de Resíduos & & Saúde e Segurança no trabalho \\
Utilização de Energia não renovável & & Valorização de Fornecedores Locais Certi- \\
ficados
\end{tabular}

FONTE: Os autores.

\section{Considerações finais}

A partir desta pesquisa, conclui-se que a integração das dimensões ambiental, econômica e social é fundamental para analisar a sustentabilidade das empresas e, dessa forma, contribuir para o desenvolvimento sustentável. As empresas precisam, atualmente, auxiliar o crescimento e o desenvolvimento socioeconômico de forma local, regional e global, bem como controlar seus impactos ambientais.

Com o aumento da população mundial e o crescimento das atividades vinculadas às subáreas do agronegócio, é preciso ter ferramentas que possam mensurar e controlar os impactos gerados por essa atividade, e que ao mesmo tempo possam identificar os benefícios econômicos e sociais para as pessoas envolvidas. Dessa forma, é possível afirmar que as empresas podem direcionar suas estratégias em busca da sustentabilidade empresarial através da mensuração dos indicadores. Existe, a nível internacional, uma infinidade de metodologias e de indicadores de sustentabilidade à disposição das empresas. Entretanto, vale ressaltar que os indicadores de sustentabilidade precisam caracterizar os valores e a cultura da organização em questão, para que os resultados possam ser mensurados de forma mais concreta.

Com exceção dos indicadores "estímulo a uma vida saudável" e "propagação das práticas orgânicas", que são específicos da pesquisa em questão, todos os outros foram identificados em diversos estudos já publicados, como: Fiksel et al. (1998), Callens \& Tyteca (1999), Azapagic \& Perdan (2000), Azapagic (2003), Corazza (2003), Keeble et al. (2003), Seuring et al. (2003), Krajnc \& Glavic (2003), Claro \& Claro (2004), Labuschagne et al. (2005), Nordheim \& Barrasso (2007), Staniskis \& Arbaciauskas (2009), Erol et al. (2009), Callado (2010), Costa (2010), Kinderyte (2010), Li et al. (2012), Tokos et al. (2012), GRI (2013), Linke et al. (2013) e Feil et al. (2015). Nesse sentido, o conjunto de indicadores proposto no estudo, se demonstra 
simples, informativo e relevante para a indústria, tendo em vista a sua aplicabilidade em outros setores. Conceber e implantar os indicadores de sustentabilidade em uma empresa exige, primeiramente, o reconhecimento de que eles precisam ser de fácil acesso e entendimento, além de representarem a real situação do momento, de forma rápida e clara para os tomadores de decisão planejarem o futuro. Dessa forma, os indicadores conseguem alcançar seus principais objetivos, que são aumentar a consciência sobre os problemas existentes na empresa, auxiliar na tomada de decisões e direcionar suas estratégias.

A seleção rápida de um conjunto de indicadores de sustentabilidade, específicos para a produção de suco de uva orgânico, é a melhor opção para as pequenas empresas iniciantes na integração dos conceitos de sustentabilidade. Além disso, para se ter uma melhor compreensão dos principais impactos gerados pela empresa, é interessante que se conheça, de forma aprofundada, cada área, identificando a fonte de problemas de forma isolada para, posteriormente, propor soluções mais eficazes para a empresa como um todo.

Pequenas empresas possuem vantagem em relação às grandes na implantação de um conjunto de indicadores, pois apresentam canais de comunicação informal, com estruturas flexíveis, pessoas multifuncionais e com acesso facilitado aos gestores, características essas que também foram identificadas pelos pesquisadores ao longo do estudo, tendo em vista a facilidade de entrevistar os gestores, e pelas diversas atividades desenvolvidas pelos colaboradores, o que também foi percebido durante as visitas. Vale ressaltar, entretanto, que a incorporação de um conjunto desse porte demanda envolvimento, tempo e investimento de funcionários de diversas áreas, a fim de alcançar melhores resultados. Diante disso, envolver os próprios funcionários nos desafios internos organizacionais pode ser um diferencial dentro das empresas.

As três empresas participantes do estudo possuem características peculiares, mas enfrentam problemas e desafios semelhantes. As três apresentam quantidade de produção de suco de uva parecido, utilização de equipamentos modernos com o objetivo de reduzir ao máximo o desperdício, e equipes de colaboradores multidisciplinares que estão sempre em busca de soluções eficazes. Entretanto, o grande desafio ainda é direcionar e/ou reaproveitar ao máximo os resíduos gerados durante o processo. Apesar de algumas soluções já terem sido identificadas, é preciso mais parcerias com Instituições de Ensino Superior, ou até mesmo envolver a comunidade, com o objetivo de desenvolver pesquisas com esse perfil. A produção orgânica está diretamente envolvida na valorização da identidade cultural presente naquele espaço, gerando também possíveis benefícios a comunidade.

Para que o conjunto de indicadores de sustentabilidade alcance resultados satisfatórios, ou seja, contribua para o direcionamento de estratégias em busca da sustentabilidade empresarial e impacte de forma positiva os três pilares de sustentabilidade, é de extrema importância refletir sobre algumas perguntas consideradas chave, tais como: o que avaliar? Como avaliar? Por quanto tempo avaliar? Por que avaliar? Que elementos constam na avaliação? De que maneiras os resultados serão expostos, integrados e aplicados? Do contrário, erros comuns podem aparecer, como medir o que é mensurável e não o que é importante, desviar a atenção de questões importantes, entre outros.

Como sugestão de implantação, os indicadores se destinam a subsidiar o processo de gestão 
ambiental na organização do setor de produção de suco de uva orgânico, com o propósito de atender os princípios da sustentabilidade. Dessa forma, eles impactam fortemente a tomada de decisões, contribuindo diretamente para a redução de impactos ambientais do processo produtivo, para a redução de custos e consequentes ganhos com receita, bem como geram benefícios para a comunidade envolvida no processo.

Como recomendações de estudos futuros, indica-se a criação de índices e subíndices para uma possível comparação entre outras agroindústrias com relação ao nível de sustentabilidade encontrado, e aprofundar pesquisas sobre a adaptação dos indicadores à gestão empresarial, pois eles precisam estar integrados ao processo gerencial ao invés de serem trabalhados de forma isolada.

\section{Referências}

Alencar, G. V. de.; Mendonça, E. de S.; Oliveira, T. S. de.; Jucksch, I.; Cecon, P. R. Percepção Ambiental e Uso do Solo por Agricultores de Sistemas Orgânicos e Convencionais na Chapada da Ibiapaba, Ceará. Revista de Economia e Sociologia Rural, 51(2), 217-236, 2013. doi: 10.1590/ S0103-20032013000200001

Andersen, B. Business Process Improvement Toolbox. Milwaukee, Wisconsin: ASQ Quality Press, 1999.

Andrade, L. M. S.; Bertoldi, M. C. Atitudes e Motivações em relação ao consumo de alimentos orgânicos em Belo Horizonte - MG. Brazilian Journal of Food Technology, 31-40, 2012. doi: 10.1590/S1981-67232012005000034

Archela, E.; Carraro, A.; Fernandes, F.; Barros, O. N. F.; Archela, R. S. Considerações sobre a geração de efluentes líquidos em centros urbanos. Revista de Geografia, 12(1), 2003. Disponível em: http://www.uel.br/revistas/uel/index. php/geografia/article/view/6711/6055

Assis, R. L. de.; Romeiro, A. R. O processo de conversão de sistemas de produção de hortaliças convencionais para orgânicos. Revista de Administração Pública, 41(5), 863885, 2007. doi: 10.1590/S0034-76122007000500004.

Azapagic, A. System approach to corporate sustainability: a general framework. Institution of Chemical Engineers, 81(5), 303-316, 2003. doi:10.1205/095758203770224342

Azapagic, A.; Perdan, S. Indicators of Sustainable Development for Industry: A general Framework. Institution of Chemical Engineers, 78(4), 243-261, 2000. doi: $10.1205 / 095758200530763$

Azevedo, E. de. Alimentos orgânicos: ampliando os conceitos de saúde humana, ambiental e social. São Paulo: Editora Senac, 2012.

Bardin, L. Análise de conteúdo. São Paulo: Ed 70, 2011.

Benitez, R. M.; Golinski, I. A agricultura orgânica como estratégia alternativa em busca da sustentabilidade: uma análise estatística da organização atual. Revista de Administração e Inovação, 4(2), 117-132, 2007. doi: 10.5585/ rai.v4i2.124

Bork, C. A. S.; Souza, J. F. de.; Gomes, J. de O.; Canhete, V. V. P.; Barba Jr, D. J. de. Methodological tools for assessing the sustainability index (SI) of industrial production processes. International Journal of Advanced Manufacturing Technology, 87, 1313-1325, 2014. doi: 10.1007/s00170014-6684-8

Brasil. Lei $n^{\circ} 10.831$, de 23 de dezembro de 2003. Dispõe sobre a agricultura orgânica e dá outras providências. Brasília: DOU de 24/12/2003. Disponível em <https://www. plan alto.gov.br/ccivil_03/leis/2003/L10.831.htm> Acesso em: abr. 2015.

Calazans, L. B. B.; Silva, G. Inovação de processo: uma análise em empresas com práticas sustentáveis. Revista de Gestão Ambiental e Sustentabilidade, 5(2), 115-129, 2016. doi: $10.5585 /$ geas.v5i2.395

Callado, A. L. C. Modelo de mensuração de sustentabilidade empresarial: uma aplicação em vinícolas localizadas na serra gaúcha. Porto Alegre, Tese (Doutorado em Agronegócios) - UFRGS, 2010. Disponível em: $<$ http://www.lume. ufrgs.br/handle/10183/26743>.

Callens, I.; Tyteca, D. Towards indicators os sustainable development for firms: a productive efficiency perspective. 
Ecological Economics, 28(1), 41-53, 1999. doi: 10.1016/ S0921-8009(98)00035-4

Camargo, U. A.; Tonietto, J.; Hoffmann, A. Progresso na viticultura Brasileia. Revista Brasileira de Fruticultura, 33, 144-149, 2011. doi: 10.1590/S010029452011000500017

Capellesso, A. J.; Cazella, A. A. Indicador de sustentabilidade dos agroecossistemas: estudo de caso em áreas de cultivo de milho. Revista de Ciência Rural, 43(12), 2297-2303, 2013. doi: 10.1590/S0103-84782013005000130

Carvalho, A. P. V.; Brumatti, D. V.; Dias, H. C. T. Importância do manejo da bacia hidrográfica e da determinação de processos hidrológicos. Revista Brasileira de Agropecuária Sustentável, 2(2), 148-156, 2012. doi: 10.21206/ rbas.v2i 2.177

Cavalcante, L. M.; Machado, L. C. G. T.; Lima, M. M. de. Avaliação do desempenho ambiental e racionalização do consumo de água no segmento industrial de produção de bebidas. Ambiente e Água, 8(3), 191-202, 2013. doi: 10.4136/ambi-agua. 1212

Chen, D.; Thiede, S.; Schudeleit, T.; Herrmann, C. A holistic and rapid sustainability assessment tool for manufacturing SMEs. CIRP Annals - Manufacturing Technology, 63, 437440, 2014. doi: 10.1016/j.cirp.2014.03.113

Clark, K. B.; Fujimoto, T. Product Development Performance: Strategy, Organization, and Management in the World Auto Industry. Boston: Harvard Business School Press, 1991.

Claro, P. B. de O.; Claro, D. P. O desenvolvimento de indicadores para monitoramento da sustentabilidade: $\mathrm{o}$ caso do café orgânico. Revista de Administração, 39(1), 18-29, 2004.

Corazza, R. I. Gestão ambiental e mudanças da estrutura organizacional. Revista de Administração de Empresas, 2(2), 2003. Disponível em: http://rae.fgv.br/rae-eletronica/ vol2-num2-2003/gestao-ambiental-mudancas-estrutura-organizacional

Costa, A. A. V. M. R. Agricultura sustentável III: Indicadores. Revista de Ciências Agrárias, 33(2), 2010. Disponível em: <http://www.scielo.mec.pt/scielo.php?script $=$ sci_ arttext\&pid=S0871 018X2010000200009>
Cruz, M. À. G.; Rindermann, R. S.; Rufino, J. O.; Tovar, L. G. Situación y desafíos del sector organic de México. Revista mexicana de ciências agrícolas. 1(4), 593-608, 2010. Disponível em: http://www.scielo.org.mx/scielo. php?script=sci_arttext\&pid=S2007-09342010000400011

Curi, D. Gestão Ambiental. São Paulo: Pearson Prentice Hall, 2012.

Delai, I.; Takahashi, S. Uma proposta de modelo de referência para a mensuração da sustentabilidade corporativa. Revista de Gestão Social e Ambiental, 2(1), 19-40, 2008. doi: $10.5773 /$ rgsa.v2i1.59

Dias, V. da V.; Schultz, G.; Schuster, M. da S.; Talamini, E.; Révillion, J. P. O Mercado de Alimentos Orgânicos: Um panorama quantitativo e qualitativo das publicações internacionais. Ambiente \& Sociedade, 18(1), 161-182, 2015. doi: 10.1590/1809-4422ASOC841V1812015en

Donaire, D. Gestão ambiental na empresa. São Paulo: Atlas, 2. ed., 1999.

Elkington, J. Sustentabilidade: Canibais com Garfo e Faca. São Paulo: M. Books, 2012.

Embrapa uva e vinho, 2015. Disponível em $<$ https://www. embrapa.br/uva-e-vinho>. Acesso em: mai. 2015.

Erol, I.; Cakar, N.; Erel, D.; Sari, R. Sustainability in the Turkish Retailing Industry. Sustainable Development, 17(1), 49-67, 2009. doi:10.1002/sd.369

Estrela, S. P. Diagnóstico de resíduos sólidos industriais em Santa Catarina. Florianópolis, Dissertação (Mestrado em Engenharia Civil) - UFSC, 1996.

Falcão, J. V.; Lacerda, M. P. C.; Mendes, I. de C.; Leão, T. P.; Carmo, F. F. do. Qualidade do solo cultivado com morangueiro sob manejo convencional e orgânico. Pesquisa Agropecuária Tropical, 43(4), 450-459, 2013. doi: 10.1590/ S1983-40632013000400004

Feil, A. A.; Quevedo, D. M. de; Schreiber, D. Selection and identification of the indicators for quickly measuring sustainability in micro and small furniture industries. Sustainable Production and Consumption, 3, 34-44, 2015. doi: 10.1016/j.spc.2015.0 8.006

Fiksel, J.; Mcdaniel, J.; Spitzeley, D. Measuring Product 
Sustainability. Journal of Sustainable Product Design, 1998.

Gabriel, D.; Sait, S. M.; Kunin, W. E.; Benton, T. G. Food production vs. biodiversity: comparing organic and conventional agriculture. Journal of Applied Ecology, 50(2), 355-364, 2013. doi: 10.1111/1365-2664.12035

Graziano, G. O.; Campanario, M. de A.; Chagas Filho, M. de F. Produtos orgânicos: as ferramentas de marketing para sua sustentabilidade econômica. Revista de Gestão Social e Ambiental, 5(3), 2011. doi: 10.5773/rgsa.v5i3.496.

Greiner, T. J. Indicators of Sustainable Production: A Case Study on Measuring Sustainability at Stonyfield Farm, Inc. Lowell Center for Sustainable Production, 2001. Disponível em: <http://www.sustainableproduction.org/abou.what. php> Acesso em: nov. 2015.

Guedes, A. C.; Torres, D. A. P.; Campos, S. K. Sustentabilidade e sustentação da produção de alimentos e o papel do Brasil no contexto global. In: Buainain, A. M.; Alves, E.; Silveira, J. M. da; Navarro, Z. (Orgs). O mundo rural no Brasil do século 21: a formação de um novo padrão agrário e agrícola. Brasília: Embrapa, p. 117-146, 2014.

GRI - Global Reporting Initiative, 2013. Diretrizes para Relato de Sustentabilidade. Disponível em: <https://www. globalreporting.org/Pages/default.aspx $>$ Acesso em: mar. 2015.

Harrington, J. Aperfeiçoando processos empresariais. São Paulo: Makron Books, 1993.

Ilic, Z. S.; Kapoulas, N.; Sunic, L.; Bekovic, D.; Mirecki, N. Heavy metal and Nitrate contente in tomato fruit grown in organic and conventional production systems. Polish Journal of Environmental Studies, 23(6), 2027-2032, 2014. doi: 10.15244/pjoes/23922

ISO - International Organization for Standardization, 2016. $<$ http://www.iso.org/iso/home.ht ml> Acesso em: jan. 2016.

Jabbour, C. J. C.; Santos, F. C. A.; Jabbour, A. B. L. de S. A importância dos fatores humanos no desenvolvimento de produtos com elevado desempenho ambiental: estudo de casos. Revista de Administração Mackenzie, 10(4), 32-56, 2009. doi: 10.1590/S1678-69712009000400003

Kamiyama, A.; Maria, I. C. de.; Souza, D. C. C. de.; Silveira, A. P. D. da. Percepção ambiental dos produtores e qualidade do solo em propriedades orgânicas e convencionais. Bragantia, 10(1), 2011. doi: 10.1590/S0006-87052011000100024

Karam, K. F. Agricultura orgânica: estratégia para uma nova ruralidade. Curitiba, Tese (Doutorado em Meio Ambiente e Desenvolvimento) - UFPR, 2001.

Keeble, J. J.; Topiol, S.; Berkeley, S. Using Indicators to Measure Sustainability Performance at a Corporate and Project Level. Journal of Business Ethics, 44, 149-158, 2003. doi: 10.1023/A:1023343614973

Kinderyte, L. Analysis and Comparison of Methodologies for Corporate Sustainability Assessment. Environmental Research, Engineering and Management, 4 (46), 66-75, 2008.

Kinderyte, L. Methodology of Sustainability Indicators Determination for Enterprise Assessment. Environmental Research, Engineering and Management, 52(2), 25-31, 2010.

Krajnc, D.; Glavic, P. Indicators of sustainable production. Clean Technology Environmental Policy, 5, 279-288, 2003. doi: 10.1007/s10098-003-0221-z

Krajnc, D.; Glavic, P. A model for integrated assessment of sustainable development. Resources, Conservation and Recycling, 43, 189-208, 2005. doi: 10.1016/j.resconrec.2004.06.002

Labuschagne, C.; Brent, A. C.; Erck, R. P. G. V. Assessing the sustainability performances of industries. Journal of Cleaner Production, 13, 373-385, 2005. doi: 10.1016/j. jclepro.2003.10.007

Li, T.; Zhang, H.; Yuan, C.; Liu, Z.; Fan, C. A PCA-based method for construction of composite sustainability indicators. Sustainable Development, 17, 593-603, 2012. doi: 10.1007/s11367-012-0394-y

Linke, B. S.; Corman, G. J.; Dornfeld, D. A.; Tönissen, S. Sustainabilty indicators for discrete manufacturing processes applied to grinding technology. Journal of Manufacturing Systems, 32(4), 556-563, 2013. doi: 10.1016/j. jmsy.2013.05.005

Lee, K.; Saen, R. F. Measuring corporate sustainability management: A data envelopment analysis approach. International Journal of Production Economics, 140(1), 219-226, 2012. doi: 10.1016/j.ijpe.2011.08.024 
Lotter, D. W. Organic agriculture. Journal of Sustainable Agriculture, 21(4), 59-128, 2003. doi: 10.1300/ J064v21n04_06

MAPA. Ministério da Agricultura, Pecuária e Abastecimento, 2015. Disponível em: <http://www.agricultura.gov.br/> Acesso em: nov. 2015.

Mazzarotto, A. de S.; Berté, R. Gestão Ambiental no Mercado Empresarial. Curitiba: InterSaberes, 2013.

Miranda, A. B. de.; Teixeira, B. A. do N. Indicadores para o monitoramento da sustentabilidade em sistemas urbanos de abastecimento de água e esgotamento sanitário. Engenharia Sanitária e Ambiental, 9(4), 269-2279, 2004. doi: 10.1590/ S14134152200 4000400002

Muñoz, C. M. G.; Gómez, M. G. S.; Soares, J. P. G.; Junqueira, A. M. R. Normativa de Produção Orgânica no Brasil: a percepção dos agricultores familiares do assentamento da Chapadinha, Sobradinho (DF). Revista de Economia e Sociologia Rural, 54(2), 361-376, 2016. doi: 10.1590/1234.56781806-947900540209

Nordheim, E. Barrasso, G. Sustainable development indicators of the European aluminium industry. Journal of Cleaner Production, 15(3), 275-279, 2007. doi:10.1016/j. jclepro.2006.02.004

North, K. Environmental business management: an introduction. Geneva: Labour Office, 1997.

Nuintin, A. A.; Nakao, S. H. A definição de indicadores do desempenho e da qualidade para o processo de produção: estudo de casos do processo de produção do café. Revista Contemporânea de Contabilidade, 7(14), 51-74, 2010. doi: $10.5007 / 21758069.2010 \mathrm{v} 7 \mathrm{n} 14 \mathrm{p} 51$

Oliveira Neto, G. C. de.; Godinho Filho, M.; Ganga, G. M. D.; Naas, I. A.; Vendrametto, O. Princípios e ferramentas da produção mais limpa: um estudo exploratório em empresas brasileiras. Gestão e Produção, 22(2), 326-344, 2015. 10.1590/0104-530X1468-14.

Orth, C. M.; Baldin, N.; Zanotelli, C. T. A geração de resíduos sólidos em um processo produtivo de uma indústria automobilística: uma contribuição para a redução. Revista Gestão e Produção, 21(2), 447-460, 2014. doi: 10.1590/0104-530X707
Prodanov, C. C.; Freitas, E. C. de. Metodologia do trabalho cientifico: Métodos e técnicas da pesquisa e do trabalho acadêmico. 2. ed. Novo Hamburgo: Editora Feevale, 2013. Disponível em: <http://www.feevale.br/Comum/midias/ 8807f05a-14d0-4d5b-b1ad-1538f3aef538/E-book\%20Metodologia $\% 20 \mathrm{do} \% 20$ Trabalho\%20Cientifico.pdf $>$ Acesso em: jun. 2015.

Rabelo, L. S.; Lima, P. V. P. S. Indicadores de sustentabilidade em cultivo de algas vermelhas. In: Philippi Jr, A.; Malheiros, T. F. (Org). Indicadores de Sustentabilidade e Gestão Ambiental. Barueri: Manole, 2012.

Rauta, J.; Fagundes, J. R.; Sehnem, S. Gestão ambiental a partir da produção biodinâmica: uma alternativa à sustentabilidade em uma vinícola catarinense. Revista de Gestão Ambiental e Sustentabilidade, 3(3), 135-154, 2014. doi: 10.5585/geas.v3i3.156

Richartz, F.; Freitas, C. L. de.; Pfitscher, E. D. Análise de sustentabilidade ambiental em uma indústria de bebidas: um enfoque no processo produtivo. Revista Contemporânea de Contabilidade, 6(12), 35-52, 2009. doi: 10.5007/2175-8069.2009v6n12p35

Rizzon, L. A.; Miele, A. Características analíticas de sucos de uva elaborados no Rio Grande do Sul. Boletim SBCTA, 29(2), 129-133, 2012.

Robertson, J. Likert-type Scales, Statistical Methods, and Effect Sizes. Communications of the ACM, 55(5), 2012. doi: $10.1145 / 2160718.2160721$

Rocha, M. C.; Barbosa, F. V.; Torga, E. M. M. F.; Carvalho, L. A. Perspectivas no processo de produção de aço: o programa arcelormittal de sustentabilidade. REUNA, 18(1), 23-40, 2013. Disponível em: <http://revistas.una.br/index. php/reuna/article/view/495/520>.

Sachs, I. Estratégias de transição para o século XXI. São Paulo: Studio Nobel, 1993.

Santos, M. R. dos.; Teixeira, C. E.; Kniess, C. T. Avaliação de desempenho ambiental na valorização de resíduos sólidos de processos industriais. Revista de Administração, 7, 2014. doi: $10.5902 / 1983465912982$

Santos, L. P. dos.; Avelar, J. M. B.; Shikida, P. F. A.; Carvalho, M. A. de. Agronegócio brasileiro no comércio 
internacional. Revista de Ciências Agrárias, 39(1), 59-69, 2016. doi: 10.19084/RCA15065

Savitz, A. W.; Weber, K. The triple bottom line: how today's best-run companies are achieving economic, social and environmental success - and how you can too. São Francisco: Jossey-Bass, 2006.

SEBRAE. Serviço Brasileiro de Apoio às Micro e Pequenas Empresas, 2016. Disponível em https://www.sebrae.com. br/sites/PortalSebrae. Acesso em: jun. 2016.

Seuring, S. A.; Koplin, J.; Behrens, T.; Schneidewind, U. Sustainability Assessment in the German detergente industry: from stakeholder involvement to sustainability indicators. Sustainable Development, 11, 199-212, 2003. doi: $10.1002 / \mathrm{sd} .216$

Scielo. Scientific Electronic Library Online. Disponível em: http://www.scielo.org/php/index.php Acesso em: abr. 2015.

Science Direct, 2015. Disponível em: http://www.sciencedirect.com/ Acesso em: abr. 2015.

Silva, A. C. R. da. Metodologia da pesquisa aplicada à contabilidade: orientações de estudos, projetos, artigos, relatórios, monografias, dissertações, teses. São Paulo: Atlas, 2. ed., 2006.

Singh, R. K.; Murty, H. R.; Gupta, S. K.; Dikshit, A. K. $\mathrm{Na}$ Overview of Sustainability assessment methodologies. Ecological Indicators, 15, 281-299, 2012. doi: 10.1016/j. ecolind.2011.01.007

Souza, A. A. de.; Azevedo, E. de.; Lima, E. E. de.; Silva, A. P. F. da. Alimentos orgânicos e saúde humana: estudo sobre controvérsias. Revista Panamericana de Salud Pública, 31(6), 513-517, 2012. doi: 10.1590/S102049892012000600010
Staniskis, J. K.; Arbaciauskas, V. Sustainability Perfomance Indicators for Industrial Enterprise Management. Environmental Research, Engeneering and Management, 48(2), 42-50, 2009.

Stevenson, W. J. Administração das Operações de Produção. Rio de Janeiro: Editora LTC, 2001.

Strasburg, V. J.; Jahno, V. D. Sustentabilidade de cardápio: avaliação da pegada hídrica nas refeições de um restaurante universitário. Revista Ambiente e Água, 10(4), 903-914, 2015. doi: 10.4136/ambi-agua. 1664

Theis, V.; Schreiber, D. Análise das Práticas Ambientais em Atividades de Inovação de Produtos e Processos. Sustentabilidade em Debate, 6(2), 155-170, 2015. doi: 10.18472/ SustDeb.v6n2.2015.12871

Tokos, H.; Pintaric, Z. N.; Krajnc, D. An integrated sustainability performance assessment and benchmarking of breweries. Clean Technologies Environmental Policy, 14, 173-193, 2012. doi: 10.1007/s10098-011-0390-0

Uvibra. União Brasileira de Vitivinicultura, 2015. Disponível em http://www.uvibra.com.br/ Acesso em: jun. 2015.

Van Bellen, H. M. Indicadores de sustentabilidade: uma análise comparativa. Rio de Janeiro: FGV, 2. ed., 2006.

Veleva, V.; Hart, M.; Greiner, T.; Crumbley, C. Indicators os sustainable production. Journal of Cleaner Production, 9(5), 447-452, 2001. doi: 10.1016/S0959-6526(01)00004-X

Wildauer, E. W.; Wildauer, L. D. B. S. Mapeamento de processos: Conceitos, Técnicas e Ferramentas. Curitiba: Intersaberes, 2015.

Yin, R. K. Estudo de caso: planejamento e métodos. Porto Alegre: Bookman 4, ed., 2010. 